\title{
The Influence of Job Characteristics and Perceived Fairness Toward Psychological Empowerment Among Public Sector Employees in Sri Lanka
}

\author{
Anuja.R \\ Department of Business \& Management Studies, \\ Trincomlaee Campus, Eastern University, Sri Lanka
}

\begin{abstract}
Nowadays organizations face new challengers in high technology and information based competitive environment. Therefore, organizations force to move towards more decentralized structure. To face new challenges, organizations should change their job characteristics from traditional structure to participative management and empowerment. Employee empowerment may be a basic significance within the competitive work environment these days. Since, it can grant the organization a supported competitive advantage. Hence, it is pivotal for organizations to decide the presence of empowerment within the work itself and to which degree the empowerment has been effectively set within the intellect of the worker. Thus, the purpose of this study is to investigate the impact on psychological empowerment and the two types of predictors namely, job characteristics and perceived fairness of among public sector employees working at district secretariats Northern Province. With a thorough review of the literature, conceptual model was developed. The study developed validated research instruments. The model was empirically tested by collecting data from public sector employees working at district secretariats Northern Province. A total of one hundred and fifty public sector employees were selected for the study using the stratified random sampling technique and one hundred and thirty six usable questionnaires were returned. To validate the items, internal consistency reliability, content validity and convergent validity was tested. Hypotheses were developed and to test hypotheses, Pearson correlation coefficient analysis and regression analysis was used with the support of Statistical Package for the Social Sciences (SPSS). The findings revealed that job characteristics and psychological empowerment of employees have a strong and significant positive relationship and its forty five percentage impact on psychological empowerment. Likewise, perceived fairness have a strong significant positive relationship and it is impact forty three percentage on psychological empowerment. Finally, job characteristics and perceived fairness impact forty eight percentage on psychological empowerment. Further, this study provided implications of the results and future direction for further research.
\end{abstract}

Keywords: Psychological Empowerment, Job Characteristics, Perceived Fairness.

DOI: $10.7176 / \mathrm{EJBM} / 12-6-07$

Publication date: February $29^{\text {th }} 2020$

\section{Introduction}

Employees are the wealthy assets for private sector organizations as well as public sector organizations. As such their behaviors must be well studied, analyzed and well organized. Well organized job characteristics and perceived fairness may leads to better performance of the organization's employees. Perhaps, the important role of human resource practices as selection or staffing and employee development programs might serve in improving the match between the job and the individual described by Fried and Ferris (1987). Samavi (2011) defined that, the contemporary dynamic environment is pressurizing organizations to keep their management techniques concurrent with the current challenges. Adopting new management approach has therefore become imperative for the organizations to meet the demands of customers and competitive environment.

Now a day's managers and researchers have started to put more attention on the influence of job design on employee's behaviors and attitudes after founding out that changes in the work environment were accompanied by changes in employee attitudes and motivation (Bakker \& Timms, 2011). As per, Jonge De. Doormann, Janssen, Dollard, Landeweered, \& Nijhuis, (2001) statement 'various studies have supported the assumption that job characteristics influence work-related psychological well-being, including job satisfaction'. Hackman and Oldham (1975) elaborated five job characteristics model which are skill variety, feedback, autonomy, task identity and task significant.

This study was designed to investigate the relationship between the three types of predictors on transfer job characteristics, perceived fairness and psychological empowerment in selected public sector organization in Sri Lanka. Therefore, this section begins with a broad introduction of the Sri Lankan public sector. Sri Lanka public sector plays vital role of economic and service sector. According to Central Bank of Sri Lanka, as per the Public Sector Employment Survey conducted by the Central Bank of Sri Lanka, the total public sector employment was 1,394,172 at the end of 2017, compared to 1,389,767 in 2016. This includes employees in Ministries, Departments, District Secretariats, Divisional Secretariats, Provincial Councils and Semi Government institutions (Central Bank 
Annual Report 2017)'.

In past three decades Sri Lanka was severely affected by local crisis, especially north and east provinces. Sri Lankan development indicators such as economic, living conditions and infrastructure were collapse by thirty years of civil war. mAfter thirty years of civil crisis Sri Lanka government's had been needed large amount skilled labor force for rebuild the nation in developing track.

Therefore, the study is necessary to employee's psychological empowerment is how essential for better and fast end results on public service. "If this empowering process of employees happens in a planned and professional way, it will definitely bring and reflect improvements in productivity individually and collectively. It also encourages innovative methodologies in the ways of delivering the services as well; give real meanings to the existence of the organizations witnessing happenings of wonders. Since public sector is the largest employer in most of the countries, it should focus on improving the productivity by empowering the employees as whole of approach of the state and this will be a part of an overall growth strategy of a country's economy. Increasing productivity is one of the most critical goals in the public sector organizations. As have seen earlier, most of the public sector organizations are full of human resource and most of the time this work force are without sufficient and reasonable assignments.

When a public sector organization decides to improve its productivity; the first priority should be placed on productive management of human resource. Managing workforce productivity involves accepting responsibility for optimizing the outputs and outcomes from human resource justifying human resource expense. The Gap is, the human resource factors may significantly influence positive or negative productivity in the public sector originations and the managers and leaders of these organizations should focus and streamline them to empower their human resource in order to improve the productivity (stated by A.C.M Nafeel Senior Consultant SLIDA 2014)". Hence, this study is focus on the psychological empowerment through job characteristics and perceived fairness in government sector Northern Province's employees. Another Gap is, study on psychological empowerment with two independent variables such as job characteristics and perceived fairness in Indonesia by (Ika Desvitasari 2012), but very few studies examine to identify the psychological empowerment with these two independent variables job characteristics and perceived fairness of employees in public sector firms in Sri Lankan context. For these this research conducted about impact of job characteristics and perceived fairness toward psychological empowerment by concerning on how employees how observe about empowerment from their own consequence in the workplace. Further, previous researches did not sufficiently explore which element factors extremely contributed to empowerment. Therefore, the current study proposed to investigate the impact of job characteristics and perceived fairness toward psychological empowerment.

\section{Literature Review}

\section{Psychological Empowerment}

The Empowerment is concept of tool that powering employees skills, resources, authority, opportunity, motivation, as well holding them accountable and liable for results of their actions, will lead to their employee satisfaction. The empowerment is conflict management tool that has been studied for fifty years, and when applied promptly; it also can be effective in improving performance, productivity and job satisfaction declared by ( Sashkin 1984, Rudolph \& Peluchette 1993 and Conner 1997). The empowerment is fundamentally a motivational process of an individual's experience of feeling enabled by (Corsun \& Enz, 1999). The empowerment is to give potential power, so that individuals have personal influences or selection over their own behavior in a work environment. And also, empowerment is closely related to people's perceptions about themselves in relation to their work environments (Bandura, 1990).

\section{Definition of Job Characteristics}

Job characteristics refers to the behavioral approach, and concept that increases the importance of jobs by it designing the job that emphasizes on its suitability and appropriateness that is measurable. The basic idea of this concept is that job characteristics will lead to high level of work motivation, empowerment and performance. In Addition, it also takes into consideration different responses of employees on different jobs.

\section{Definition of Perceived Fairness}

Theory of organizational justice may be defined as the study of fairness at work (Byrne and Cropanzano, 2001). In the organizational justice researchers generally agree that fairness can be divided into two primary types with a third, less clearly defined type often proposed. In the first generally accepted type of justice is referred to as distributive justice. And distributive justice considers the fairness of the outcomes of a particular decision. Second Procedural justice, the second type, is generally defined as the fairness of the process that leads to the outcome. These two areas form the backdrop of majority of research conducted in the field in the last twenty years (Byrne \& Cropanzano, 2001). A third type of justice is often referred to as interactional justice. According to Bies and Moag (1986) definition interactional justice as the fairness of the interpersonal treatment that one receives at the 
hands of an authority figure. And Bies (1987) stretch this idea by adding the concept of social justice to the factor. Based on individuals' inputs, such as effort, experience, education, and competence, individual can compare outcomes such as pay, recognition and other factors (Rafikul\& Ahmad, 2008).

According to, Geralis and Terziovski defined empowerment as involving delegation of responsibility from management to employees, and collapsing hierarchical forms of organization (as cited by Elele\& Fields, 2010). The managerial subordinates are more likely to exhibit high levels of task performance and to make extra contributions to the organization when they experience psychological empowerment (Huang et al., 2010). And also, job characteristics can contribute to certain psychological concepts, and the power of the employee's need for growth (Garg\&Rastogi, 2006). Further the five characteristics of jobs contribute to three critical psychological states in the individual; experienced meaningfulness of the work, experienced responsibility for outcomes of work, and knowledge of the actual results of work activities(Yukl\& Becker, 2006; Elanain, 2009). Moreover the role of empowerment as a strategy or an intervention that strengthens an employee's self-efficacy or confidence in accomplishing task objectives (Ugboro, 2006). In addition, removing unnecessary bureaucratic controls and constraints will ease the successful completion of tasks (Yukl\& Becker, 2006). Hence, from this theory hypothesis were developed.

\section{H1: Job characteristics positively impact on psychological empowerment}

In the contemporary, empowerment plays a vital character in an organization of different sectors. In the reality there are more than 70 percent of organizations have adopted empowerment as initiative for their workforce (Ambad \& Bahron, 2012). According to Ali (2013) findings, there was a significant positive relationship between

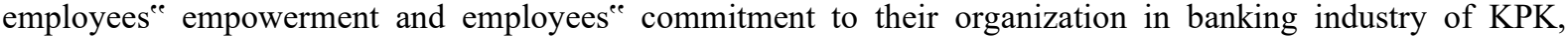
Pakistan. And then Empowerment has positive effect on organizational commitment in IT executives of Indian software industry (Jha, 2012).

Further, the psychological well-being of an employee can be affected by perceived fairness. And also, when an individual did not experience interactional justice, group support, or perceived there to be procedural justice in the organization, it was found to result in psychological stress (Rousseau et al., 2009). In acceptance, it was found that when there is distributive, procedural, or interactional injustices, it resulted in psychological strain on the worker (Francis \& Barling, 2005).

\section{H2: Perceived Fairness positively impact on psychological empowerment.}

According to Fried and Ferris (1987) found that organizational decisions to enrich jobs should be contingent upon whether contextual factors, such as the reward system or management policy, support such an intervention. Further Kamalian, Yaghoubi, and Moloudi (2010) declare, that enhancing the level of organizational justice will cause the increasing in empowerment. Therefore, if organizations want to achieve empowerment, they should invest as acceptable both justice and fair in their organization (Kamalian et al., 2010).Based on the previous explanations, the researcher also conducted one more hypothesis as follows:

\section{H3: both job characteristic and perceived fairness impact on psychological empowerment} Figure 1: Theoretical Framework of the Study

\section{Job Characteristics}

- Skill Variety

- Task Identity

- Task Significant

- Autonomy

- Feedback

\section{Perceived Fairness}

- Distributive Justice

- Procedural Justice

- Interactional Justice
Psychological Empowerment

- Meaning

- Competence

- Self- Determinant

- Impact 


\section{Methodology}

\section{Population and Sample for the Study}

The objective of this study is finding impact of job characteristics and perceived fairness toward psychological empowerment in public sector organization. Therefore the population of the research is, employees working in district secretariats Northern Province, which are Vavuniya, Mannar, Mullaithivu, Kilinochchi and Jaffna. The stratified random sampling method was used. 150 questionnaires were issued out of which 145 questionnaires were received and 09 questionnaires were rejected because poor data loading, finally 136 questionnaires were used for the final analysis.

\section{Measures}

To measure the respondent's perception on below items, five points Likert Scale was used ranging from strongly disagree (1) to strongly agree (5).

Job Characteristics : Job Characteristics was measured with 5 dimensions such as, Skill Variety, Task Identity, Task Significant, Autonomy and Feedback and each dimensions measured by 3 items.

Perceived Fairness: Perceived Fairness was measured with three dimensions namely, Distributive justice, Procedural justice and Interactional Justice and each dimensions measured with 5 items.

Psychological Empowerment: Psychological Empowerment is measured with four items such as, Meaning, Competence, Self- Determinant and Impact and each were measured by three items.

\section{Reliability and Validity of the Scales}

To validate the scales, 136 samples were carried out and reliability, content validity and convergent validity were examined. The following Table 1 . Shown the results of the above test.

\section{Reliability}

Reliability of the instrument was measured through evaluating the internal consistency among the items. According to Sekaran,(2003) the reliability of a measure indicates the extent to which it is unbiased (error free) and hence ensures consistent measurement across time and across the various items in the instrument. The internal consistency reliability is tested using an accepted method suggested by Cronbach. He proposed coefficient Alpha (called Cronbach Alpha) for multi-point scaled items.The higher the coefficients, the better the measuring instrument (Sekaran, 2003).

In addition, Alpha coefficient values more than 0.7 are acceptable indicators of internal consistency as suggested in literature (Nunnally, 1967). In the present study Cronbach Alpha used to test the reliability of the measures used in the instrument. The data in Table 3.3 clearly explores that all the variables exceeded the accepted value of Cronbach's alpha of 0.7 . Therefore, it ensured that internal consistencies among the items were reliable.

\section{Validity}

The measure is considered valid when it actually measures what it is intended to measure (Churchill, 1979). According to Sekaran (200), validity is the evidence that the instrument, technique, or process used to measure a concept does indeed measure the intended concept where content validity ensures that the measure includes an adequate and representative set of items that tap the concept and face validity indicates that the items that are intended to measure a concept, do on the face of it look like they measure the concept. Validity ensures the ability of a scale to measure the intended concept. This study used content validity to measure the instrument.

\section{Content Validity}

According to Carmines and Zeller (1991) content validity can be defined as the extent to which a measurement reflects the specific intended domain of content (Carmines \& Zeller, 1991, p.20). In this study employed following strategies to ensure content validity of the measurement.

- All the variables are derived from the literature and operationalization of the variables were developed after a thorough literature review

- As per guide lines of the supervisor the questionnaire and measurement scales were validated.

- In order to examine the process, the variables of the research scales and it relevance to the target population was examined

- To test the suitability and acceptability of the research questionnaire was tested through a pilot study.

Based on these strategies, the research scales used in this study are considered to possess content validity.

Therefore, the pilot study results showed that the survey instrument achieved adequate levels of reliability and validity and therefore the researcher continued with all items in the survey instrument for the purpose of the main analysis. 


\section{Method of Data Analysis}

Two types of methods were used in the data analysis. Firstly is descriptive statistics and secondly the Pearson correlation technique processed using the SPSS.

Descriptive Statistics of Research Variables

Research variables of Job Characteristics, Perceived Fairness and Psychological Empowerment were analyzed through mean and standard deviation by using the SPSS version 21.0

Table 3: Result of Hypotheses Testing

\begin{tabular}{|l|l|l|l|}
\hline Hypotheses & $\begin{array}{l}\text { Correlation } \\
\text { coefficient (r) }\end{array}$ & P value & $\begin{array}{l}\text { Accepted/ } \\
\text { not accepted }\end{array}$ \\
\hline $\begin{array}{l}\text { Hypothesis 1: } \\
\text { job characteristics and psychological empowerment }\end{array}$ & 0.673 & 0.000 & Accepted \\
\hline $\begin{array}{l}\text { Hypothesis 2: } \\
\text { Perceived Fairness on Psychological Empowerment }\end{array}$ & 0.663 & 0.000 & Accepted \\
\hline $\begin{array}{l}\text { Hypothesis 3: } \\
\text { job characteristic and Perceived fairness on Psychological } \\
\text { Empowerment }\end{array}$ & 0.699 & 0.000 & Accepted \\
\hline
\end{tabular}

(Source: Survey Data)

The findings showed that there were significant positive relationships among all the three variables with the Psychological Empowerment. The strength of association between job characteristics and Psychological Empowerment is strong $(\mathrm{r}=0.673)$ and that the correlation coefficient is statistically significant different from zero $(\mathrm{P}<0.001)$. The Perceived Fairness and Psychological Empowerment $(\mathrm{r}=0.663)$ also had direct significant relationship with Psychological Empowerment. job characteristic and Perceived fairness $(r=0.699)$ also significantly correlated with Psychological Empowerment. Based on the findings, all hypotheses were accepted. Furthermore, the summary result of total variance in the Psychological Empowerment is explained by the predictors reported in Table 4. It shows that job characteristic; Perceived fairness explained 79.5 percent of the total variance in Psychological Empowerment.

Table 4: Multiple Regression Analysis Results

Model Summary

\begin{tabular}{|l|l|l|l|l|}
\hline Model & R & R Square & Adjusted R Square & Std. Error of the Estimate \\
\hline 1 & $.892^{\mathrm{a}}$ & .795 & .786 & .294 \\
\hline
\end{tabular}

a. Predictors: (Constant), job characteristic, Perceived fairness, Psychological Empowerment.

\section{Discussion}

The result of testing the hypothesis 1 revealed that simple regression analysis was conducted between job characteristics and psychological empowerment, the correlation result of these variables. The result of correlation indicates that there is a strong positive correlation between job characteristics and psychological empowerment. The correlation value was $0.673(\mathrm{R}=0.673)$, it shows that the strength of association between the two variables is strong. Additionally, the value of coefficient of determination or R-square is $0.453(\mathrm{R} 2=0.453)$, which mean it the $45.3 \%$ of variance in psychological empowerment is affected by job characteristics while the rest $54.7 \%$ were affected by other factors that are not considered in this study.

The relationship between perceived fairness and psychological empowerment was also tested using simple regression analysis. Model summary result for the correlations between perceived fairness and psychological empowerment where there is a strong positive correlation between those variables. As can be seen, the correlation of those variables was $0.663(\mathrm{R}=0.663)$ which is indicated as strong correlation. Furthermore, $\mathrm{R}$-square is 0.439 $(\mathrm{R} 2=0.439)$, which means that $43.9 \%$ of variance in psychological empowerment has been affected by perceived fairness at the same time the rest of $56.1 \%$ has been affected by other factors as said in earlier, that factors are not considered in this research. Overall, the result indicates that the increased presence of perceived fairness positively related to the psychological empowerment.

\section{Implications of the Study}

The current study findings provided necessary of following implications. The current study step down the empirical gap by finding the role of psychological empowerment of government employees. The findings of the research, the job characteristic and perceived fairness positively impact to psychological empowerment in government sector employees. And also in recently increasing public sector employment trend in Sri Lanka is clearly depicted in (Central Bank Annual Report 2017), was largely due to the enhancement of employment in the government sector in 2008 and 2017 by 11.38 per cent, which contributed. This situation urged immediate intervention by the top administrates to manage this important resource towards augmentation of productivity in the sector. If the organizations attention on these is not properly paid it will cause rather than producing good 
results, devastate all the operations and ultimately lead to the downfall of the sector. In present situation, empowering employees of Sri Lankan public sector organizations with regard to productivity policy may have increasing trends. It can support to reduce failures are recorded in reaching their vision. To enhance the productivity of employee should have increase the empowerment.

In additionally, to implementing empowerment practices in the organization, it allows service employees to make on-the-spot decisions to satisfy customer completely (Robbins \& Judge, 2007). By the way of exploration of the perceptions, beliefs and feelings of empowerment the importance of competence and control in the form of decision making and problem solving is identified. Moreover, the flexibility of the work structure and decision making are distributed to the operational stage in organization are also become part of the empowerment practices. The reduction of bureaucracy would encourage the desire to employees to deliver innovative idea. An organization will be more innovative if the structure is with the decentralized and flexible system (Widjajanti, 2011). Moreover, for employees with a strong power motivation, an empowerment program would seem to be important both as a means of buffering the stress involved in unsatisfactory relationship with customers and as a way of increasing motivation (Yagil, 2006). In this case, good and fair work environments affect the state of motivation in the degree of psychological empowerment.

\section{Limitation and Recommendation}

Even though the current study findings provided a new insight based on the conceptual model in this study, it still provides a direction for future research. Firstly, the objective of the current study was to explore the impact among the variables of Job characteristics (Skill Variety, Task Identity, Task Significant, Feedback and Autonomy) and Perceived Fairness (Distributive Justice, Procedural Justice and Interactional Justice) Toward Psychological Empowerment (Meaning, Competence, Self-Determinant and Impact) among the district secretariat employees in the Northern Province). Therefore, it did not focus on all Sri Lankan government sector employees. Further, studies may benefit from an exploration of a wider range of employees at different organizations in Sri Lanka. Future research studies may focus on exploring the relationship among the determinants of psychological empowerment among private organizations.

Furthermore, the current study is limited to examine only the impact of two independent variable toward the psychological empowerment. Many other factors also are impact to psychological empowerment like Job satisfaction, Motivation, Work environment and Training and development. Therefore, future studies could include the other related factors that influence psychological empowerment. The organization can understand the strength of an employee by studying how much they feel themselves psychologically empowered (Jha, 2011). And also, in order to provide better external validity and increase the generalizability of the results, data should be collected from a larger number of respondents from the organizations. In addition, flatter organizational structures have pushed decision making down to lower levels in organizational hierarchies; these new decision-makers must be empowered with self-leadership skills and abilities in order to effectively respond to their increased responsibilities (Carson \& King, 2005). Hence, training programs should address the complexities of functioning under a high level of empowerment and provide the information, skills and knowledge that are required for a successful independent performance (Yagil, 2006). Further, the current study used a new measure of self-report of psychological empowerment and it showed a positive moderate impact by job characteristic and Perceived fairness. It would be valuable to conduct a future study which compares the current study results with those that are used as other acceptable measure of psychological empowerment Finally, in order to provide better external validity and increase the generalizability of the results, data should be collected from a larger number of respondents from the varies organizations.

\section{REFERENCES}

Bagheri, G., Matin, H. Z., \& Amighi, F. (2011).The relationship between empowerment and organizational citizenship behavior of the pedagogical organization employees. IranianJournal of Management Studies (IJMS), 4, 53-62.

Baird, K., \& Wang, H. (2010). Employee empowerment: Extent of adoption and influential factors. Personnel Review, 39, 574- 599.

Blader, S. L., \& Tayler, T. R. (2003). A fourcomponent model of procedural justice: Defining the meaning of a "fair" process. Personality and Social Psychology Bulletin, 29, 747-758.

Bogler, R., \& Somech, A. (2004). In uence of teacher empowerment on teachers' organizational commitment, professional commitment and organizational citizenship behavior in schools. Teaching and Teacher Education, 20, 277-289.

Bontis, N., Richards, D., \& Serenko, A. (2011). Improving service delivery. Investigating the role of information sharing, job characteristics, and employee satisfaction. The Learning Organization, 18, 239-250.

Boudrias, J.-S., Gaudreau, P., Savoie, A., \& Morin, A. J. S. (2009). Employee empowerment. From managerial practices to employees' behavioral empowerment. Leadership \& Organization Development Journal, 30 , 
625-638.

Carson, C. M., \& King, J. E., Jr. (2005). Leaving leadership: Solving leadership problems through empowerment. Management Decision, 43, 1049-1053.

Cavana, R. Y., Delahaye, B. L., \& Sekaran, U. (2001). Applied business research: Qualitative and quantitative methods. Australia: John Wiley \& Sons Australia.

DeConninck, J., \& Bachmann, D. (2005). An analysis of turnover among retail buyers. Journal of Business Research, 58, 874-882. 